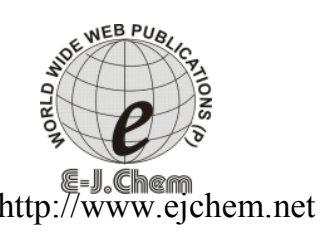

\title{
Determination of Energy Characteristic and Microporous Volume by Immersion Calorimetry in Carbon Monoliths
}

\author{
JUAN CARLOS MORENO-PIRAJÁN ${ }^{1 *}$, LILIANA GIRALDO ${ }^{2}$, and DIANA P. VARGAS ${ }^{2}$ \\ ${ }^{1}$ Departamento de Química, \\ Facultad de Ciencias. Grupo de Investigación en \\ Sólidos Porososy Calorimetría, Universidad de los Andes, \\ Carrera $1^{\mathrm{a}} \mathrm{N}^{\circ} 18^{\mathrm{a}}-10$, Bogotá, Colombia \\ ${ }^{2}$ Departamento de Química, \\ Facultad de Ciencias. Universidad Nacional de Colombia, \\ Avenida Carrera $30 \mathrm{~N}^{\circ}$ 45-03 Bogotá. Colombia \\ jumoreno@uniandes.edu.co
}

Received 13 May 2011; Revised 14 May 2011; Accepted 5 June 2011

\begin{abstract}
Activated carbon monoliths disc and honeycomb type were prepared by chemical activation of coconut shell with zinc chloride at different concentrations, without using a binder. The structures were characterized by $\mathrm{N}_{2}$ adsorption at $77 \mathrm{~K}$ and immersion calorimetry into benzene. The experimental results showed that the activation with zinc chloride produces a wide microporous development, with micropore volume between 0,38 and $0,79 \mathrm{~cm}^{3} \mathrm{~g}^{-1}$, apparent BET surface area between 725 and $1523 \mathrm{~m}^{2} \mathrm{~g}^{-1}$ and immersion enthalpy between 73,5 and $164,2 \mathrm{Jg}^{-1}$. We compared the experimental enthalpy with calculated enthalpy by equation StoeckliKraehenbuehl finding a data dispersion from which can infer that the structures are not purely microporous; this fact is ratified with similar behavior that the evidence $t$ the product EoWo.
\end{abstract}

Keywords: Carbon monolith, Chemistry activation, Immersion enthalpy, Characteristic energy.

\section{Introduction}

In microporous solids such as activated carbons, the specific surface parameter loses some of its physical meaning as the micropores seem to be filled with a liquid adsorbate, due to the adsorption potential created in the same ${ }^{1}$.

The most appropriate model to describe adsorption on microporous solids is based on the theory of micropore volume filling, TVFM developed by Dubinin et al. ${ }^{2,3}$ where the main phenomenon is the filling of the pore volume and not of surface covering such as BET model. The theory of micropore filling volume (TVFM) is based on potential theory of Polany $1^{1}$, introduced to explain the adsorption of gases on microporous solids. Polanyi's 
model, consider a series of equipotentials on the surface of the solid, adsorbate molecules are placed on these surfaces, which are assumed in the liquid state, thus defining a space or volume between these surfaces and the solid surface. Based on this theory, Dubinin made the description of adsorption on microporous solids, where filling the micropore volume is the fundamental concept that is associated to a limit value of adsorption and this in turn is related to the coefficient of thermal expansion adsorbate. Dubinin's theory led to interesting results from the thermodynamic point of view, and particularly in the field of immersion calorimetry, a method that is related to the characteristic energy of adsorption and micropore volume of porous solids. Dubinin shows that for a microporous solid with no external surface, the enthalpy of immersion in liquid is given by ${ }^{4}$ :

$$
-\Delta H_{i}(T)=\int_{0}^{l} q^{\text {net }}(T ; \theta) d \theta
$$

Where: $\mathrm{q}_{\text {net }}$ is the net heat of adsorption, which by definition is the isosteric heat, $\mathrm{q}_{\text {isot }}$, minus the enthalpy of vaporization, $\Delta \mathrm{H}_{\mathrm{VAP}}$, the adsorbent, $\theta$ is the filling fraction of the micropores. The isosteric heat is the heat evolved in the adsorption process when the latter is considered a constant coverage. Stoeckli et al. ${ }^{5,6}$ provide a relationship between the enthalpy of immersion on different types of carbon in various body fluids. The parameters obtained in the adsorption of vapors. In the equation of Stoeckli, et al.:

$$
-\Delta H_{i}=\frac{\beta E_{o} W_{o} \sqrt{\pi}(1+\alpha T)}{2 V_{m}}
$$

Where $\beta$ is the coefficient of affinity of the adsorbate, Eo is the free energy for adsorption property of a reference vapor, $\mathrm{W}_{\mathrm{o}}$ total volume of the micropores of the solid, $\alpha$ is the thermal expansion coefficient of the adsorbate at temperature $\mathrm{T}$ and $\mathrm{Vm}$ is the molar volume. When the above equation applies directly to carbons with small external area, the experimental enthalpy $\left(\Delta \mathrm{H}_{\mathrm{exp}}\right)$ also contains a contribution due to the outer surface $\left(\mathrm{S}_{\mathrm{ext}}\right)$ as the point Stoeckli, Bansal and Donet ${ }^{6}$.

$$
\Delta H_{\exp }=\Delta H_{i}+h_{i} S_{\text {ext }}
$$

Where $h_{i}$ is the specific enthalpy of immersion of an open non-porous surface. Activated carbon is an adsorbent with good adsorption properties for different pollutants, this adsorbent can occur in fibers, powders, granules, fabrics, and other monolithic structures ${ }^{7,8}$. At present, the carbon monoliths called because of their characteristics are becoming adsorbents and catalyst supports effective for environmental decontamination. The monolith word means "one stone" and refers to items such as compact disc-type monoliths and honeycomb. The latter are unitary structures traversed lengthwise parallel channels, which are a new concept in the design of catalysts and absorbent support presented: low values of load loss of gases to step facilitating the smooth flow of the same, high property mechanical, a large geometric surface per unit weight or volume, also behave as nearly adiabatic systems and reduce the constraints generated by internal diffusion phenomena ${ }^{9-13}$. In this paper we study six samples of monoliths, three diskshaped and three honeycomb, on determining adsorption isotherms and immersion calorimetry in benzene, with data from the characteristic energy is calculated for each sample and micropore volume. 


\section{Experimental}

The coconut shell is crushed and sieved using a particle size of 38 micrometers. The precursor is impregnated with a dehydrating agent; in this case zinc chloride (1 gram of precursor for $2 \mathrm{~mL}$ of solution) for 7 has $358 \mathrm{~K}$. These subjected to drying at $383 \mathrm{~K}$ for approximately 2 hours. The following is a press axis, where the shaping is done by pressing at $423 \mathrm{~K}$ and different pressures using two types of molds for the production of records and combs $^{9-13}$. These structures are burning in a furnace at a temperature of $773 \mathrm{~K}, \mathrm{~N}_{2}$ flow 85 $\mathrm{mL} \cdot \mathrm{min}^{-1}$ and a range of warming of $1^{\circ} \mathrm{Cmin}^{-1}$ for 2 hours. Finally, washed with $0.1 \mathrm{M}$ hydrochloric acid and distilled water to neutral $\mathrm{pH}$ to remove traces of chemical agent used in the impregnation ${ }^{11-13}$. Different concentrations of $\mathrm{ZnCl}_{2} 20 \%, 32 \%$ and $48 \% \mathrm{~W} / \mathrm{v}$, are used to prepare the samples of monoliths (disk and comb) symbolized by the letters MD to hard disks and MP for combs, followed in both cases the concentration initial impregnation used for each sample: MD20, MD32, MD48, MP20, MP48 MP32 and held constant other conditions. Getting a degree of impregnation $\left(\mathrm{Xg} \mathrm{Zng}^{-1}\right.$ precursor) for the series of 0.19 , 0.30 , and 0.46 respectively, which were verified by atomic absorption analysis of metal content in each monolith.

\section{Characterization of structures with adsorption isotherms of nitrogen}

All activated carbon monoliths were characterized by physical adsorption of $\mathrm{N}_{2}$ at $77 \mathrm{~K}$ using a Quantachrome equipment, Autosorb 3-B, the samples were previously degassed at $250^{\circ} \mathrm{C}$ for 3 hours. The micropore volume was calculated by applying the DubininRadushkevich equation and the surface area was obtained by BET method.

\section{Immersion heat}

The samples were also characterized by immersion calorimetry in benzene $(0.37 \mathrm{~nm})$ using a Calvet type equipment ${ }^{14}$. The enthalpies of immersion of the monoliths prepared in benzene are determined in a heat conduction microcalorimeter, calorimetric cell with a stainless steel. Weigh between 150 and $200 \mathrm{mg}$ of solids in a glass vial, and are degassed for $3 \mathrm{~h}$ at $523 \mathrm{~K}$, then sealed the vial, which is assembled cell calorimeter contains $10.0 \mathrm{~mL}$ of benzene, when the team reaches thermal equilibrium, the vial is broken, the solid is wetted by the liquid and the heat generated is recorded as a function of time. Finally, is electrically calibrated.

\section{Results and Discussion}

Figure 1 shows the monoliths obtained, the structures have a diameter of $1.6 \mathrm{~cm}$ with a height of $0.6 \mathrm{~cm}$, cross-channel honeycomb monoliths are $0.2 \mathrm{~cm}$ in diameter.

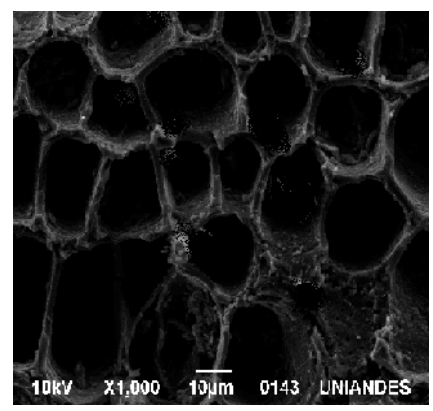

(a)

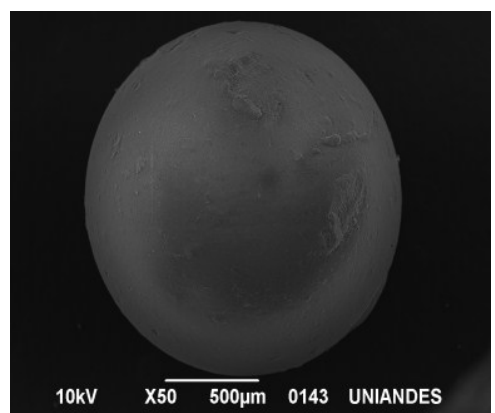

(b)

Figure 1. Monoliths obtained. a) Honeycomb type, b) Disc type. 
Figure 2 shows that the experimental conditions of impregnation, pressing, and carbonization used in the preparation of disc-shaped monoliths, and Honeycomb, possible to obtain microporous solids, a fact that is justified as type I isotherms. Likewise, there is a considerable amount of nitrogen adsorbed $500 \mathrm{~cm}^{3} \mathrm{~g}^{-1}$, which checks the adsorption capacity in these solids.

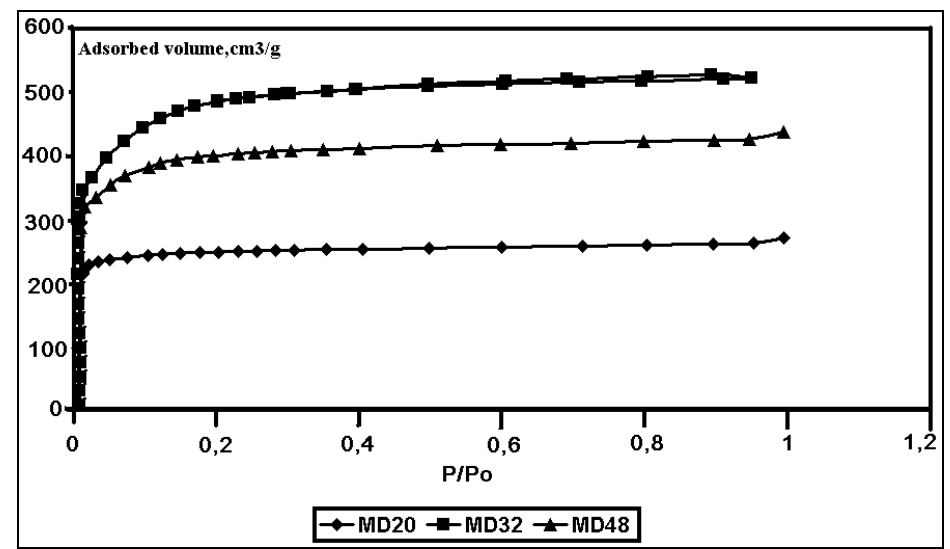

(a)

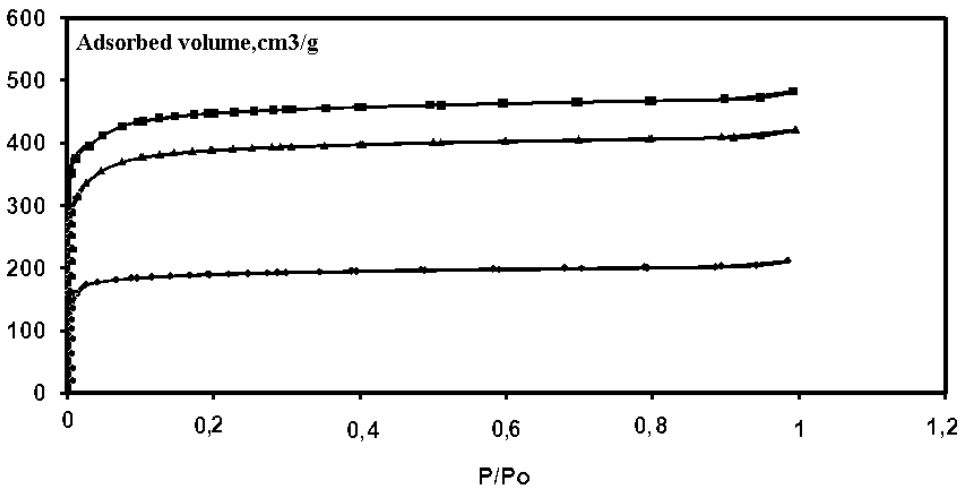

$\rightarrow \mathrm{MP} 20=-\mathrm{MP} 32-\mathrm{MP} 48$

(b)

Figure 2. Adsorption isotherms of $\mathrm{N}_{2}$ at $77 \mathrm{~K}$ ) Discs b) Honeycomb at different concentrations of $\mathrm{ZnCl}_{2}$.

Figure 2 shows that samples MP20 and MD20 a volume of nitrogen adsorbed close to $230 \mathrm{~cm}^{3} \mathrm{~g}^{-1}$, so for this concentration of impregnating no differences in their adsorption capacity even if you change the shape of the structures. In samples MP48 MD48 and similar behavior was observed as described above, and for samples MP32 MD32 and the difference in the volumes of gas adsorbed is close to $50 \mathrm{~cm}^{3} \mathrm{~g}^{-1}$, adsorbing a total volume of $500 \mathrm{~cm}^{3} \mathrm{~g}^{-1}$. This shows that these conditions of preparation $\left(32 \% \mathrm{ZnCl}_{2}\right)$ yield the best features of adsorption structures. Thus, the prepared activated carbon monoliths have surface areas between 725 and $1523 \mathrm{~m}^{2} \mathrm{~g}^{-1}$ and micropore volume between 0.39 and $0.79 \mathrm{~cm}^{3} \mathrm{~g}^{-1}$ as presented in Table 1, results are satisfactory considering the reports recent developments in the preparation of these materials that results have been obtained BET area between 500 and $2500 \mathrm{~m}^{2} \mathrm{~g}^{-1}$ and a micropore volume between ${ }^{11-13} 0.2$ and $1.4 \mathrm{~cm}^{3} \mathrm{~g}^{-1}$. The results of the disks 
and combs show that a ratio of 0.30 is achieved by impregnation of the maximum value of apparent surface area and micropore volume, this being independent of process performance.

Table 1. Characteristics of activated carbon monoliths, MCA.

\begin{tabular}{|c|c|c|c|c|c|}
\hline Monolith & $\begin{array}{l}\text { Impregnated } \\
\text { ratio }\end{array}$ & $\begin{array}{c}\text { Micropore } \\
\text { volume, } \mathrm{cm}^{3} \mathrm{~g}^{-1}\end{array}$ & $\begin{array}{l}\text { Bet area, } \\
\mathrm{m}^{2} \mathrm{~g}^{-1}\end{array}$ & Yield & $-\underset{\mathrm{Jg}^{-1}}{\Delta \mathrm{Himm}^{-}}$ \\
\hline MP20 & 0,19 & 0,39 & 726 & $45,9 \%$ & 73,5 \\
\hline MP32 & 0,30 & 0,72 & 1.315 & $50,8 \%$ & 134,1 \\
\hline MP48 & 0,46 & 0,62 & 1.170 & $53,7 \%$ & 117,5 \\
\hline MD20 & 0,19 & 0,45 & 821 & $35,1 \%$ & 90,2 \\
\hline MD32 & 0,30 & 0,79 & 1.523 & $45,1 \%$ & 164,2 \\
\hline MD48 & 0,46 & 0,65 & 1.206 & $51,9 \%$ & 132,1 \\
\hline
\end{tabular}

Immersion calorimetry were performed in benzene in the samples obtained after degassing, obtaining enthalpy values between 73.5 and $164.2 \mathrm{Jg}^{-1}$, the data reported in Table 1 indicate a direct relationship between the surface area and enthalpy data, as seen with large areas greater enthalpy, which is the expected behavior because there is a greater surface ready to interact with the adsorbate ${ }^{15}$. The higher immersion enthalpies were 164.2 and 134.1 $\mathrm{Jg}^{-1}$ corresponding to the monoliths MD32 and MP32 respectively. Figure 3 shows a comparison between the thermograms of the series of disc-shaped monoliths, the first peak corresponds to the contact between the solid and benzene and the other peak corresponds to an electrical calibration. It is noted that the magnitude of the peak in each sample is consistent with the heat of immersion obtained, being higher on the monolith MD32, MD48 and finally followed by MD20, which have areas that bear the same proportionality.

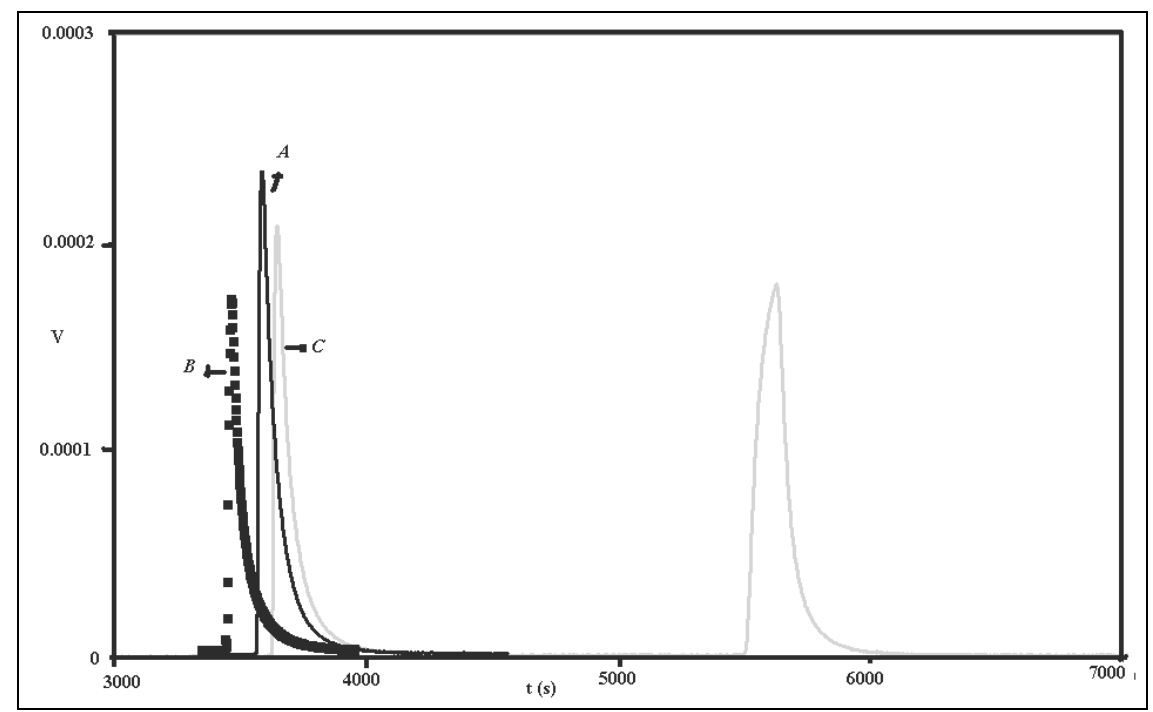

Figure 3. Calorimetry thermograms obtained for the immersion in benzene of the series) MD32 b) MD20 c) MD48 immersion peaks d) Calibration peaks. 
Figure 4 presents the graphs obtained by applying data from nitrogen isotherms Dubinin-Radushkevich model, shows the linearity of the data obtained for the series of monoliths, and this behavior demonstrates compliance with the DR equation for all samples of disk and honeycomb monoliths. These findings are important given that the model of Dubinin Radushkevich, DR, is based on Polanyi's potential theory and considers the process of filling the micropores are produced as a liquid to fill a container, so that the concept specific surface is replaced by the volume of micropores. However, as the concept of surface area is so widespread, it is accepted for use in microporous materials in comparative form, provided that specific area is called equivalent. The distribution of pore size influences very significantly the access of molecules to the inner surface of the solid or active sites. As discussed, a strong high specific surface area is associated, in general, to an important microporosity, thus, the smaller the average pore diameter, the greater the value of specific surface $^{16}$.

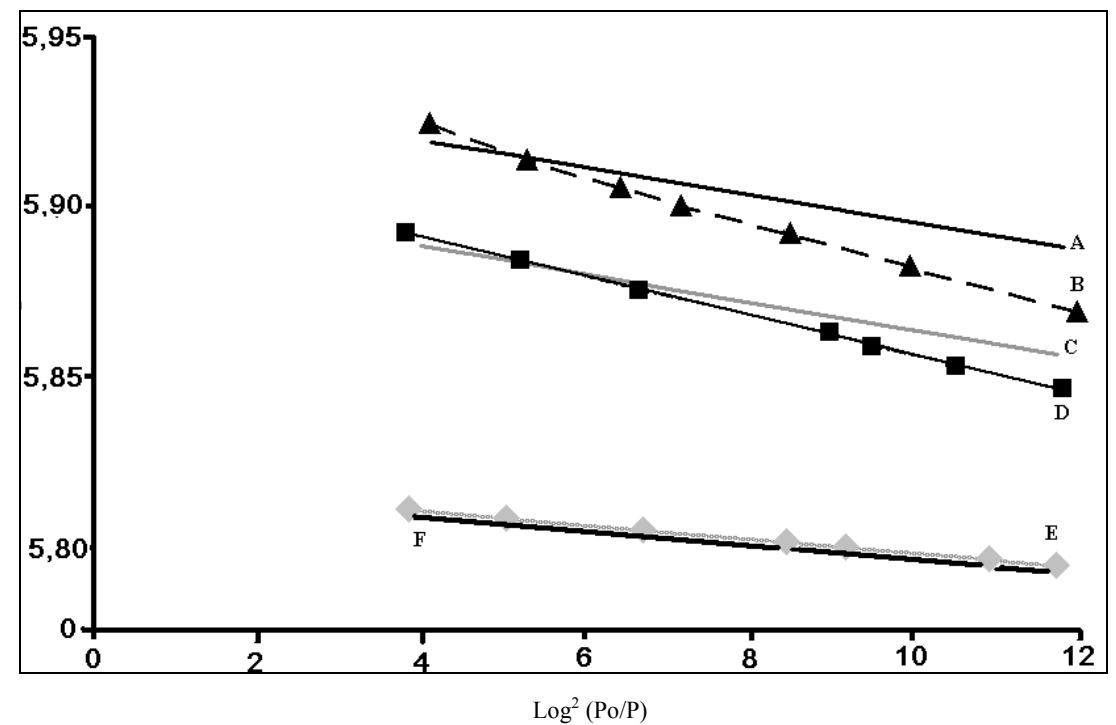

Figure 4. Representation Dubinin-Radushkevich model and comb drives. A) MP32, B) MD32, C) MP48, D) MD48, E) MP20, F) MD20.

Figure 5 shows the relation between immersion enthalpy determined experimentally with the calculated by the equation of Stoeckli-Kraehenbuehl. According to reports in the literature in those coals containing experimental enthalpy microporosity is approximately equal to that calculated by the equation. However, there is a scattering of data suggesting that the monoliths do not meet this generality, since these materials have some mesoporosity and a surface area larger than the granular activated carbons with presentation. The calculation of micropore volume and characteristic energy obtained from the $\mathrm{N}_{2}$ isotherm for comparison, so the result you get is interesting because it shows that the experimental enthalpy is less than that is calculated that the interaction between solids and benzene is less than that would be presented for solids of a high percentage of micropores and show that the provision of material affects the characteristics enthalpic. 


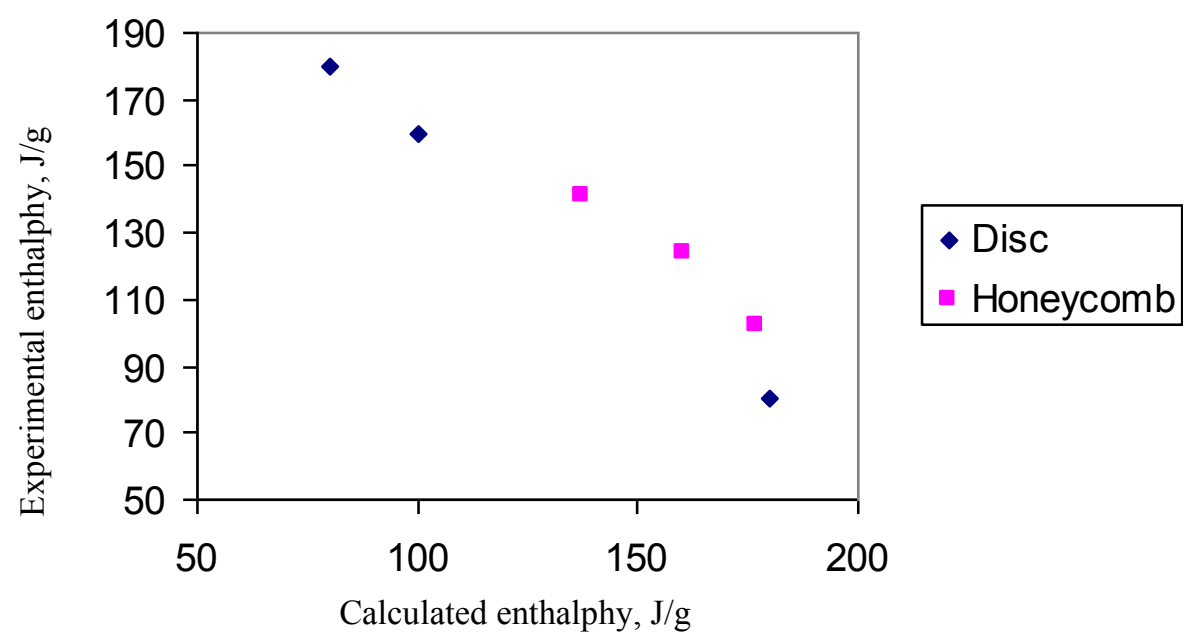

Figure 5. Immersion enthalpy experimental as function of immersion enthalpy calculated by the equation Stoeckli-Kraehenbuehl. Equation: $\mathrm{Y}=0,702 \mathrm{X}+212,12, \mathrm{R}^{2}=0,995$.

The values of micropore volume, $\mathrm{W}_{\mathrm{o}}$ and the characteristic energy, $\mathrm{E}_{\mathrm{o}}$, can be evaluated with data from the Dubinin-Radushkevich model, and the product of these relate to the accessible area, this parameter is determined by reference to a solid Carbon Black non-porous surface area $30 \mathrm{~m}^{2}$ $/ \mathrm{g}$, to calculate the specific enthalpy of the probe molecule. In this case, the evidence for the monolithic comb drive and a decline in output, with the increase in accessible surface area, this coincides with the increase of micropore volume (Figure 6). The decrease in the characteristic energy with increasing surface area of the monoliths is related to the increased amount of mesopores in the material, since the adsorption energy decreases with increasing pore size.

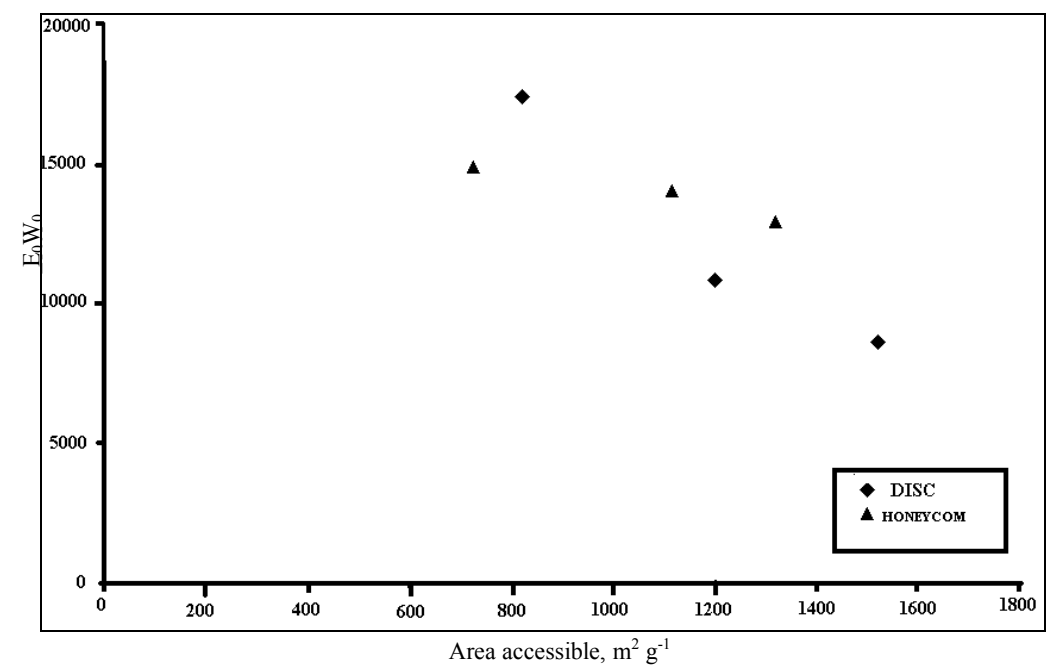

Figure 6. Product $\mathrm{E}_{\mathrm{o}} \mathrm{W}_{\mathrm{o}}$ data determined with Dubinin-Radushkevich model based on the area accessible. 
Figure 7 shows a linear behavior between $\mathrm{E}_{\mathrm{o}} \mathrm{W}_{\mathrm{o}}$ product determined by the equation of Stoeckli-Kraehenbuehl enthalpy data with experimental and accessible area, as evidenced by correlation coefficients of 0.9996 to 0.9991 for the Activated carbon dics type and honeycombs, this being consistent with a greater accessible area found that $\mathrm{W}_{\mathrm{o}}$ increases, as shown in Table 1, also can see a higher value product for samples $\mathrm{E}_{\mathrm{o}} \mathrm{W}_{\mathrm{o}}$ disc type monoliths compared to bees, this is logical considering that the disks have a higher microporosity and therefore greater capacity for adsorption and interaction energy with adsorbate.

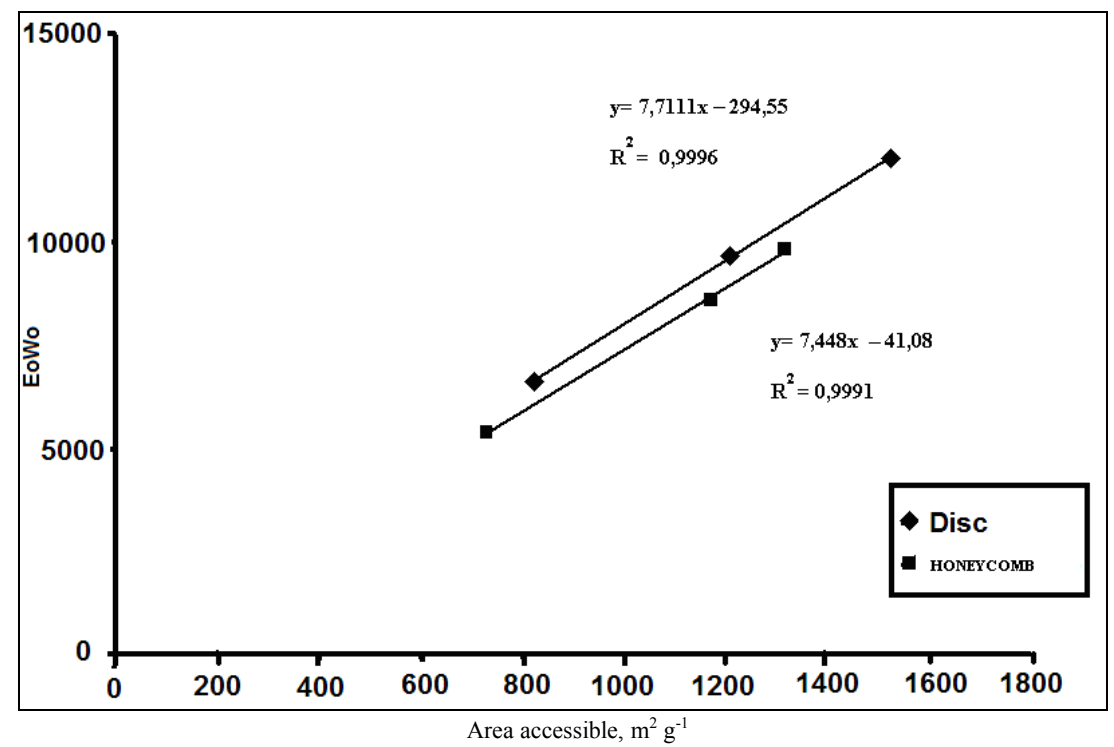

Figure 7. Product $\mathrm{E}_{\mathrm{o}} \mathrm{W}_{\mathrm{o}}$ determined by the equation of Stoeckli-Kraehenbuehl according to the area accessible.

\section{Conclusion}

The immersion calorimetry in benzene showed a correlation between BET area and enthalpy, finding values between $73.5 \mathrm{Jg}^{-1}$ and $164.2 \mathrm{Jg}^{-1}$. The comparison is usually made between the experimental and calculated enthalpy by the equation of Stoeckli-Kraehenbuehl applicable to microporous solids, do not throw a correlation between the data. However, we found a good correlation between the product $\mathrm{E}_{\mathrm{o}} \mathrm{W}_{\mathrm{o}}$ determined by equation of StoeckliKraehenbuehl with the experimental entalphy data and the BET area. Using $\mathrm{ZnCl}_{2}$ impregnating agent is favorable for the synthesis of activated carbon monoliths used as coconut shell precursor material, the structures that have good properties are obtained adsorbents. Six samples were prepared carbon monoliths (discs, and honeycombs), BET areas getting between 702 and $1523 \mathrm{~m}^{2} \mathrm{~g}^{-1}$, and micropore volumes between $0.38 \mathrm{~cm}^{3} \mathrm{~g}^{-1}$ and $0.79 \mathrm{~cm}^{3} \mathrm{~g}^{-1}$. The best characteristics were obtained in samples MD32 (disks) and MP32 (honeycombs) which were obtained under the same conditions, varying only the shape of the structures.

\section{Acknowledgment}

The authors thank the Framework Agreement between the Universidad de los Andes and Universidad Nacional de Colombia and the Act of Understanding between the Departments of Chemistry at the two universities. Special thanks to Fondo Especial de la Facultad de Ciencias and Proyecto Semilla of Universidad de los Andes for the partial financial of this research. 


\section{References}

1. Stoeckli. H F Bansal R C and Donnet J B, ”Active Carbon”. Marcel Dekker (Editors) New York, Bansal. 1988. pp. 20-45.

2. Brunauer S, Emmett P H and Teller E, J Am Chem Soc., 1938, 60, 309.

3. Dubinin M M, Chem.Rev., 1960, 60, 235.

4. Dubinin M M, Polyakov N S, Kataeva L I and Petuvhova G A, Russ Chem Bull., 1993, 42(8), 1304.

5. Stoeckli H F, Carbon, 1981, 19, 325.

6. Stoeckli H F and Kraehenbüehl F, Carbon, 1989, 27, 125.

7. Yates M, Blanco J, Avila P and Martin M P, Microp Mesop Mater., 200, 37, 201.

8. Nakagawaa Y, Molina-Sabio M and Rodríguez-Reinoso F, Microp Mesop Mater., 2007, 103, 29.

9. Blanco M P, Martín C and Avarez E, Environ Eng Sci., 2000, 17(4), 215.

10. Laishuan Liu, Carbon, 2006, 44,1581.

11. Caturla F, Molina-Sabio M and Rodríguez-Reinoso F, Carbon, 1991, 29, 999.

12. Molina-Sabio M, Almansa $\mathrm{C}$ and Rodríguez-Reinoso, F, "Procedimiento para la obtención de monolitos de carbón activado, monolitos obtenidos y su empleo", Patente España 2, 2003, 165, 784.

13. Almansa C, Molina-Sabio M and Rodríguez-Reinoso F, Microp Mesop Mater., 2004, 76, 185.

14. Moreno J C and Giraldo L, Inst Sci Technol., 2000, 28(2), 171.

15. Silvestre-Albero J and Gómez de Salazar C, Sepúlveda-Escribano A and RodríguezReinoso F, Colloid Surfaces A, 2001, 187, 151.

16. Martín-Martínez J M, "Capítulo 5: Porosidad de carbones. II. Teoría de PolanyiDubinin,”. En Adsorción física de gases y vapores por carbones. Vol 3. Universidad de Alicante. 1990. pp. 11-31, ISBN: 84-86809-33-9.

17. Moreno J C, Giraldo L and Gómez A, Inst Sci Technol., 1998, 26(5), 533. 


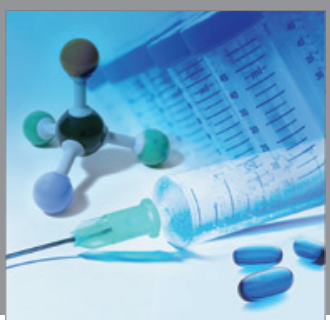

International Journal of

Medicinal Chemistry

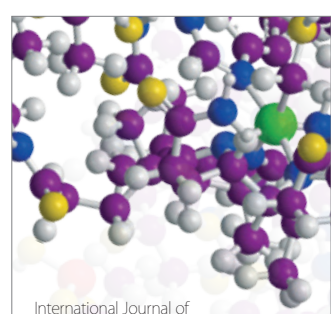

Carbohydrate Chemistry

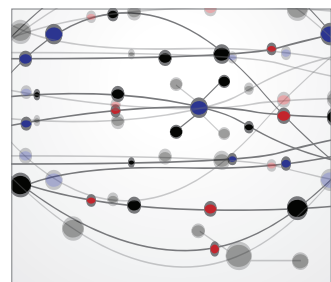

The Scientific World Journal
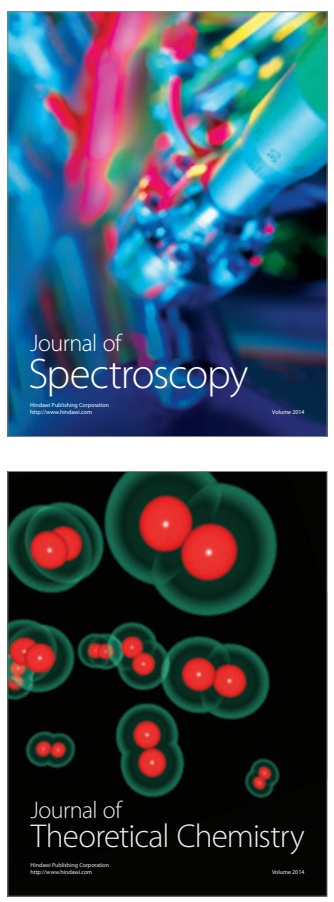
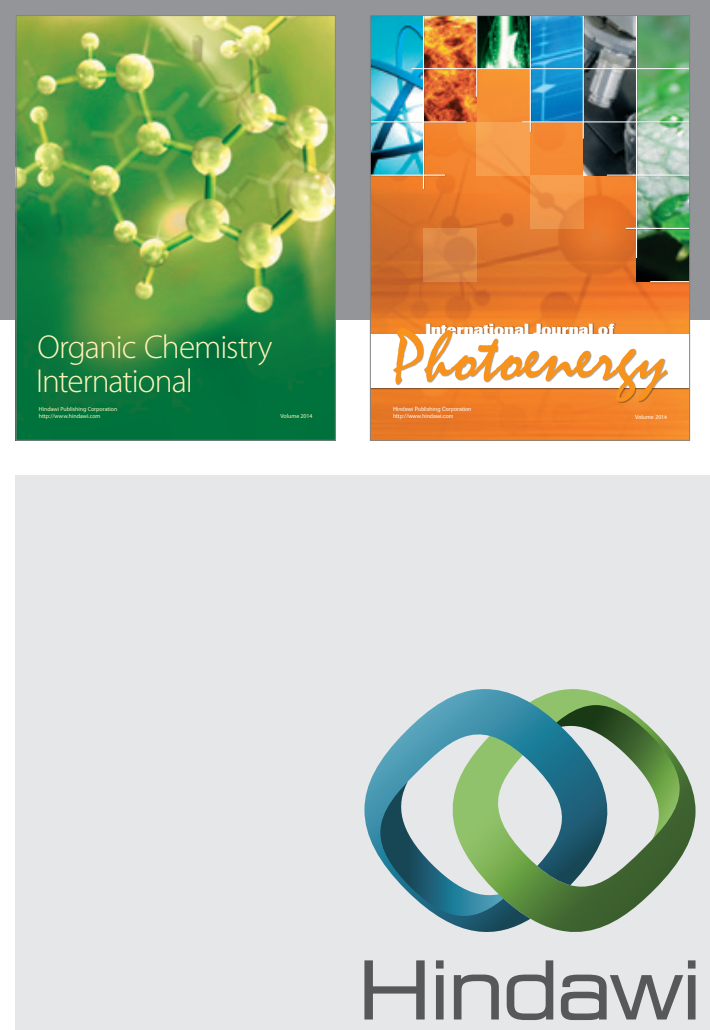

Submit your manuscripts at

http://www.hindawi.com
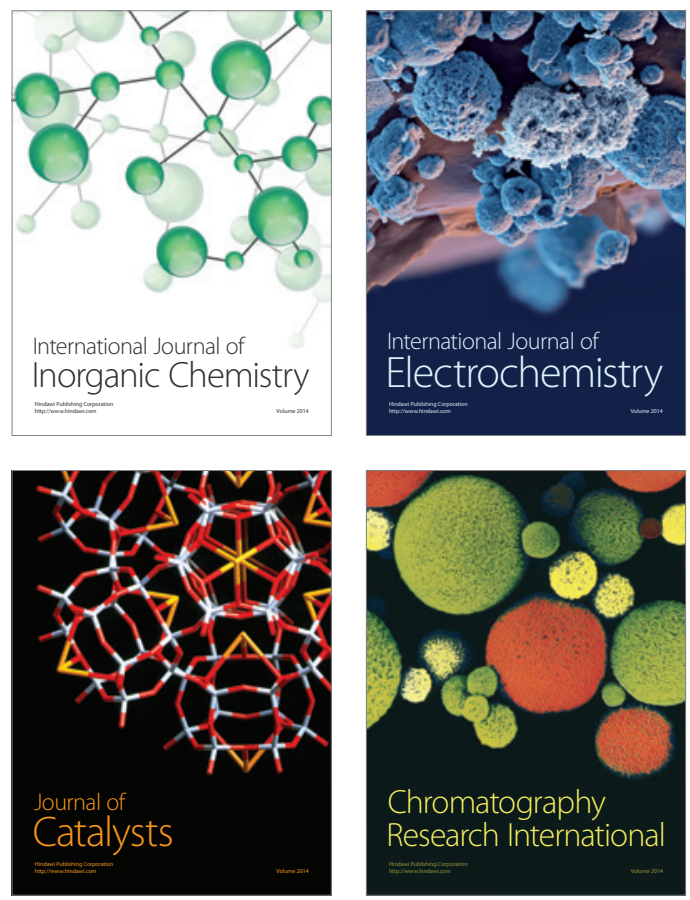
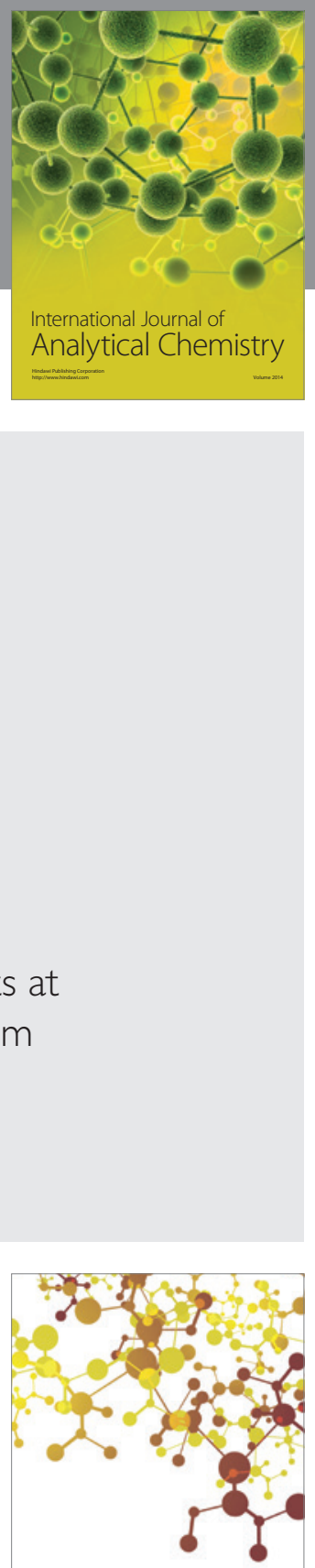

Journal of

Applied Chemistry
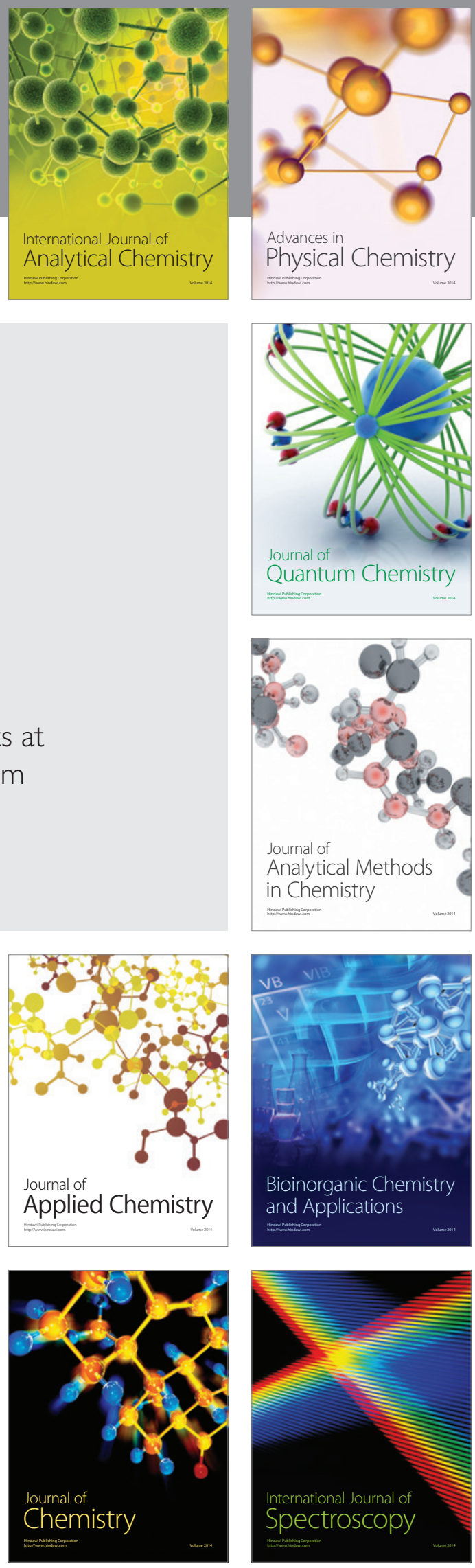